\title{
Modelos didáticos para ensino inclusivo de Física Nuclear
}

\author{
Didactic models for inclusive teaching of Nuclear Physics
}

\author{
Carla Mariana da Silva Pinheiro ${ }^{1}$ \\ Monique França e Silva ${ }^{2}$ \\ Ana Paula Perini ${ }^{3}$ \\ Lucio Pereira Neves ${ }^{4}$
}

\section{RESUMO}

Diante do cenário de ausência e superficialidade do ensino de Física Nuclear, preconceitos e mitos sobre o tema em questão e escassez de materiais didáticos voltados para alunos com deficiência, o presente trabalho traz a ação extensionista na construção e aplicação de material didático para o ensino e divulgação científica dos conceitos de energia nuclear. Seu diferencial é o caráter tátil das maquetes, com detalhes em relevos e texturas trabalhadas com $\mathrm{o}$ intuito de possibilitar o ensino a alunos com deficiência visual. $\mathrm{O}$ material segue a cronologia do emprego da energia nuclear para fins bélicos, apresentando os processos de fusão e fissão nuclear e, posteriormente, as diferentes bombas criadas e utilizadas ao longo da Segunda Guerra Mundial e do período da Guerra Fria. Finaliza com o esquema de uma usina termonuclear, apresentando a geração de energia elétrica a partir de processos nucleares. $\mathrm{O}$ trabalho foi aplicado em um evento de divulgação científica que contava com a presença de alunos com e sem deficiência visual, que interagiram e aprenderam a partir do material elaborado. Por fim, essas ações contribuíram para a formação dos alunos da graduação envolvidos no projeto.

Palavras-chave: Ensino de Ciências. Física Nuclear. Deficiência Visual.

\begin{abstract}
Considering the absence and superficiality of Nuclear Physics teaching, prejudices, and myths about the subject in question, and scarcity of teaching materials tailored for visually impaired students, the present work brings the extension action, in the construction and application of didactic material for the teaching and scientific dissemination of nuclear energy concepts. Its differential is the tactile character of the models whose reliefs and textures were made for enabling the teaching of visually impaired students. The material followed the chronology of nuclear energy, from war purposes, presenting the nuclear fusion and nuclear fission processes and right after the different bombs created and used during the World War II and the Cold War. It ends with a thermonuclear plant model, presenting the generation of electric energy from nuclear processes. The work was applied in a scientific dissemination event that counted on the presence of some visually impaired students who interacted and learned from

\footnotetext{
1 Mestranda em Matemática na Universidade de São Paulo, São Paulo, Brasil; bolsista FAPESP. (carla.pinheiro@usp.br).

${ }^{2}$ Doutoranda em Engenharia Biomédica na Universidade Federal de Uberlândia, Minas Gerais, Brasil; bolsista Capes; subcoordenadora do Programa Meninas na Física. (franca_monique@ufu.br).

${ }^{3}$ Doutora em Tecnologia Nuclear pela Universidade de São Paulo, Brasil; professora da Universidade Federal de Uberlândia, Minas Gerais, Brasil; coordenadora do Programa Meninas da Física. (anapaula.perini@ufu.br).

${ }^{4}$ Doutor em Tecnologia Nuclear pela Universidade de São Paulo, Brasil; professor na Universidade Federal de Uberlândia, Minas Gerais, Brasil; membro do Grupo de Pesquisa Ionizing Radiation Dosimetry in Medicine; coordenador do Laboratório de Instrumentação e Dosimetria (LInDa) e do Programa Meninas da Física. (lucio.neves@ufu.br).
} 
the elaborated material. Finally, these actions contributed to the formation of undergraduate students involved in the project.

Keywords: Nuclear Physics. Science teaching. Blindness.

\section{INTRODUÇÃO}

A importância de investir tempo e recursos em pensar o ensino de Física Nuclear reside em dois pilares: de um lado tem-se a relevância indiscutível da energia nuclear no que tange às aplicações médicas e industriais e, do outro, o preconceito popular com relação ao uso dessa fonte de energia. Tal preconceito tem raízes na falta de conhecimento e nas falácias que se incorporaram ao saber popular ao longo das últimas décadas. Segundo Simons (1987) e Hewitt (2009), a população apresenta temor ou medo em relação à Física Nuclear por associar sempre aos malefícios da aplicação da radioatividade e aos acidentes nucleares provenientes das bombas e usinas nucleares. Uma vez que há barreiras para transmitir os conhecimentos científicos com uma linguagem acessível e descomplicada para a população, essas barreiras acarretam "a falta de acesso a uma educação científica de qualidade para o cidadão entender os assuntos científicos" (COSTA; BORTOLIERO, 2010, p. 14).

A falta de conhecimento, na educação básica, sobre a Física Nuclear também está relacionada a diversos fatores, entre eles, ausência ou abordagem superficial do conteúdo, capítulos isolados nos livros didáticos, escassez de materiais didáticos, e carência de laboratórios e experimentos (CARVALHO NETO; FREIRE JÚNIOR; ROCHA, 1999; PEREIRA; AGUIAR, 2006; MORAIS; GUERRA, 2013). Portanto, uma alternativa para quebrar alguns preconceitos e mitos, os quais vão desde a exaltação da energia nuclear como fonte infinita de energia até a crença de que usinas nucleares representam um risco à vida humana, é o desenvolvimento de técnicas e materiais para o ensino e a divulgação científica do assunto que sejam interessantes, atrativos e, acima de tudo, inclusivos (CARVALHO, 2012).

Em relação aos materiais inclusivos, nota-se que há carência de recursos didáticos voltados para os alunos com deficiência visual (NUNES; LOMÔNACO, 2010; NEPOMUCENO; ZANDER, 2015; BAPTISTONE et al., 2017), principalmente para o ensino e divulgação científica dos conceitos e fenômenos da Física (FERREIRA; DICKMAN, 2007; MACHADO, 2010). Quando uma atividade se volta para o ensino de alunos com deficiência visual, Camargo (2012) aponta dois aspectos que urgem alguma forma de compensação, a saber, o significado vinculado às representações visuais e o significado 
indissociável de representações visuais. Ou seja, os materiais didáticos devem ser "adequados ao conhecimento tátil-cinestésico, auditivo, olfativo e gustativo" (ROSS; VOOS, 2017, p. 2), os quais proporcionam melhores condições de desenvolvimento e aprendizagem do aluno com deficiência visual. Ferreira e Dickman (2007) apontam que os professores precisam de formação pedagógica sobre a educação especial (inclusiva) e experiências com alunos cegos para a construção desses materiais didáticos e adequação das suas aulas. Porém, Amaral, Dickman e Ferreira (2009) alertam que muitos alunos de cursos da licenciatura se formam sem realizarem disciplinas de educação especial (inclusiva) e estágios com alunos com deficiência.

Portanto, dois professores e uma aluna do curso de Bacharelado em Física da Universidade Federal de Uberlândia (UFU), em 2018, preocupados com os cenários do ensino básico e os conhecimentos da população sobre a Física Nuclear, desenvolveram algumas maquetes para inclusão dos alunos com deficiência visual. A intenção com essa ação foi tentar explicar fenômenos muito abstratos de forma simples e acessível. Como os aspectos básicos envolvendo a energia nuclear apresentam apenas representações visuais, uma forma de tornar o trabalho acessível seria criar maneiras alternativas de relacionar o significado dos fenômenos a modelos táteis. Assim, o ponto de equilíbrio encontrado entre criar um trabalho simples, de fácil manuseio e explicação pelo docente ou intermediário a conduzir a atividade, e acessível também a estudantes com deficiência visual, foi a confecção de maquetes detalhadas nos relevos e texturas para uso em aula e em atividades de divulgação científica.

Diante do exposto, o objetivo deste trabalho é apresentar a construção e a aplicação de modelos que foram desenvolvidos como material auxiliar no ensino de Física, podendo ser utilizados tanto em salas de aula quanto para divulgação científica e afins. Todas as peças foram pensadas para facilitar ao mediador a explanação do conteúdo abordado, a saber, energia nuclear, e ao interlocutor a identificação e diferenciação de cada componente abordado. As peças são belas e coloridas, atraindo a atenção dos alunos e possuem um trabalho delicado com relevos e contrastes de textura no intuito de promover a inclusão dos estudantes com deficiência visual. Além disso, relatar a experiência e a importância dessa ação de extensão na formação das pessoas envolvidas.

\section{MATERIAIS E MÉTODOS}

As maquetes foram confeccionadas artesanalmente, utilizando os seguintes materiais: 
a) Placas de MDF $30 \mathrm{~cm} \times 40 \mathrm{~cm} ; 40 \mathrm{~cm} \times 60 \mathrm{~cm} ; 10 \mathrm{~cm} \times 10 \mathrm{~cm} ; 20 \mathrm{~cm} \times 30 \mathrm{~cm}$;

b) Tinta fosca para artesanato e tinta de tecido de cores diversas;

c) Jornais, pincéis macios, espátulas de biscuit, cola para biscuit, cola para isopor, tesoura, palitos de dente, palitos de churrasco, cola de madeira, palitos de picolé, papel cartão, fio de sisal, lápis preto, lixa de unha;

d) Verniz fosco e verniz brilhante;

e) Amido de milho e massa de biscuit.

Uma explicação detalhada da confecção de cada modelo se encontra nas subseções seguintes.

\section{RESULTADOS E DISCUSSÃO}

\section{Fissão e fusão nuclear}

A descoberta da fissão nuclear foi creditada a Otto Hahn, laureado com o Nobel de Química em 1944 (NOBELPRIZE.ORG, 2021). Entretanto, é importante destacar que outra cientista essencial para esta descoberta, Lise Meitner, não foi laureada. Sem ela é bem provável que Hahn não tivesse chegado tão longe, visto que Hahn e Meitner sempre se corresponderam para explicar esse fenômeno, tendo, inclusive, se encontrado em Copenhagen, Dinamarca, em 1938 (MIZRAHI, 2005).

A fissão nuclear consiste na quebra de um núcleo pesado, devido a algum processo físico, o caso do $92235 \mathrm{U}$, a colisão com um nêutron, gerando energia e outros elementos químicos, como por exemplo $56139 B a+3694 K r+301 n$ (UFRGS, 2016).

Ao contrário da fissão nuclear, a fusão nuclear é o processo em que há a junção de dois núcleos para formar um mais pesado. Esse processo ocorre constantemente em estrelas! Nesse processo, também há a liberação de grandes quantidades de energia (UFRGS, 2016).

A primeira maquete elaborada foi uma representação didática dos processos de fusão e fissão nuclear. A base foi feita com a placa de MDF de $20 \mathrm{~cm} \times 30 \mathrm{~cm}$, a qual foi tratada com cola de madeira para maior resistência. Usando biscuit e bolinhas de isopor para fazer o esqueleto, foram construídos os átomos de urânio, bário e criptônio. Ainda em biscuit, foram criadas as representações dos átomos de hélio e hidrogênio, além dos nêutrons. Por fim, foram pintadas as equações de reação e o material foi envernizado com verniz brilhante para conferir acabamento à peça. A proposta é que o professor ou intermediário que se propusesse a ensinar 
a fissão e a fusão nuclear ao estudante com deficiência visual guiasse as mãos do aluno à medida que explicasse cada fase do processo com o auxílio das equações descritas no MDF.

\section{Chicago Pile 1}

A segunda peça é uma representação do primeiro reator nuclear construído pelo homem. Para a base foi utilizada uma placa de MDF tratada com cola de madeira, pintada com tinta fosca para artesanato nas cores branco e preto, e envernizada com verniz fosco. $\mathrm{O}$ reator foi feito com esqueleto de papel cartão, coberto por biscuit, tingido com tinta fosca e palitos de dente cortados. O biscuit foi envernizado com verniz fosco, e palitos de churrasco e de picolé fizeram a trilha do mecanismo de ativação do reator. Por fim, foi construído o piso superior, de onde os cientistas manipularam o experimento com um computador que tem o tamanho aproximado de uma pessoa em escala (Figura 1).

A proposta é que o/a aluno/a possa perceber, pelo tato, a arquitetura e, em especial, as proporções do primeiro reator nuclear construído pela humanidade. Novamente, o professor guiaria o aluno, explicando cada parte do modelo e seu funcionamento.

Figura 1 - Representação didática do reator nuclear Chicago Pile 1

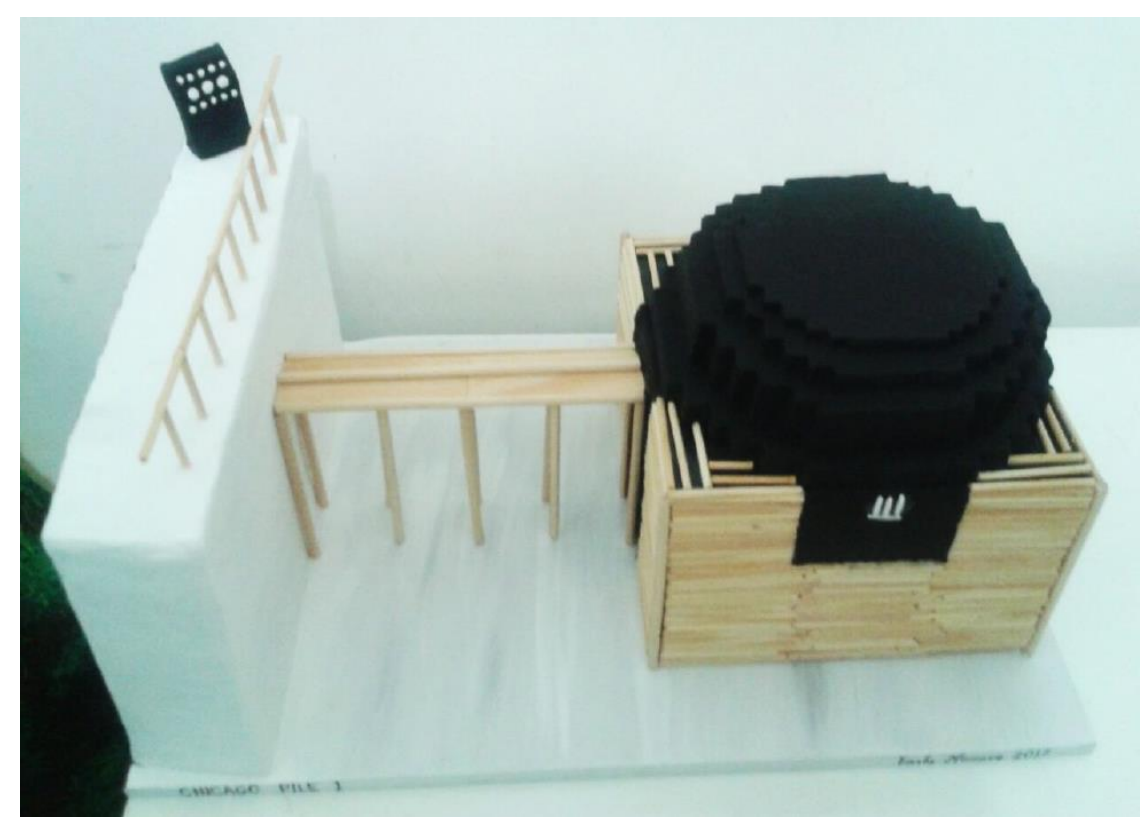

Fonte: Os autores (2020). 


\section{Bombas atômicas}

A terceira parte da construção do material envolveu a criação de uma representação do primeiro teste de bomba atômica realizado pelos Estados Unidos, o famoso teste Trinity. A base de MDF de $30 \mathrm{~cm} \times 40 \mathrm{~cm}$ foi tratada com cola de madeira e coberta com areia. As marcas das explosões anteriores foram pintadas no solo e o cogumelo de explosão foi construído de papel machê (feito a partir dos jornais) e coberto com biscuit. Em seguida, foi pintado e envernizado. O contraste de texturas entre a areia e o biscuit possibilita a percepção das dimensões do cogumelo e, consequentemente, do poder de destruição da arma.

Ademais, foram confeccionados modelos dos três protótipos básicos de bombas utilizadas na Segunda Guerra Mundial e na Guerra Fria, a saber, a bomba de fissão de urânio Little Boy (Figura 2), a bomba de fissão de plutônio Fat Man (Figura 3), a bomba de hidrogênio Tsar Bomb (Figura 4) e um cogumelo formado pela explosão de um artefato nuclear (Figura 5). As três foram construídas respeitando as proporções entre elas, com o mecanismo de detonação trabalhado em detalhes e toda a sua configuração interna com alto relevo.

O professor poderia explorar as proporções das bombas, assim como as diferenças dos mecanismos de detonação entre elas.

Figura 2 - Representação da bomba Little Boy lançada sobre Hiroshima em 1945

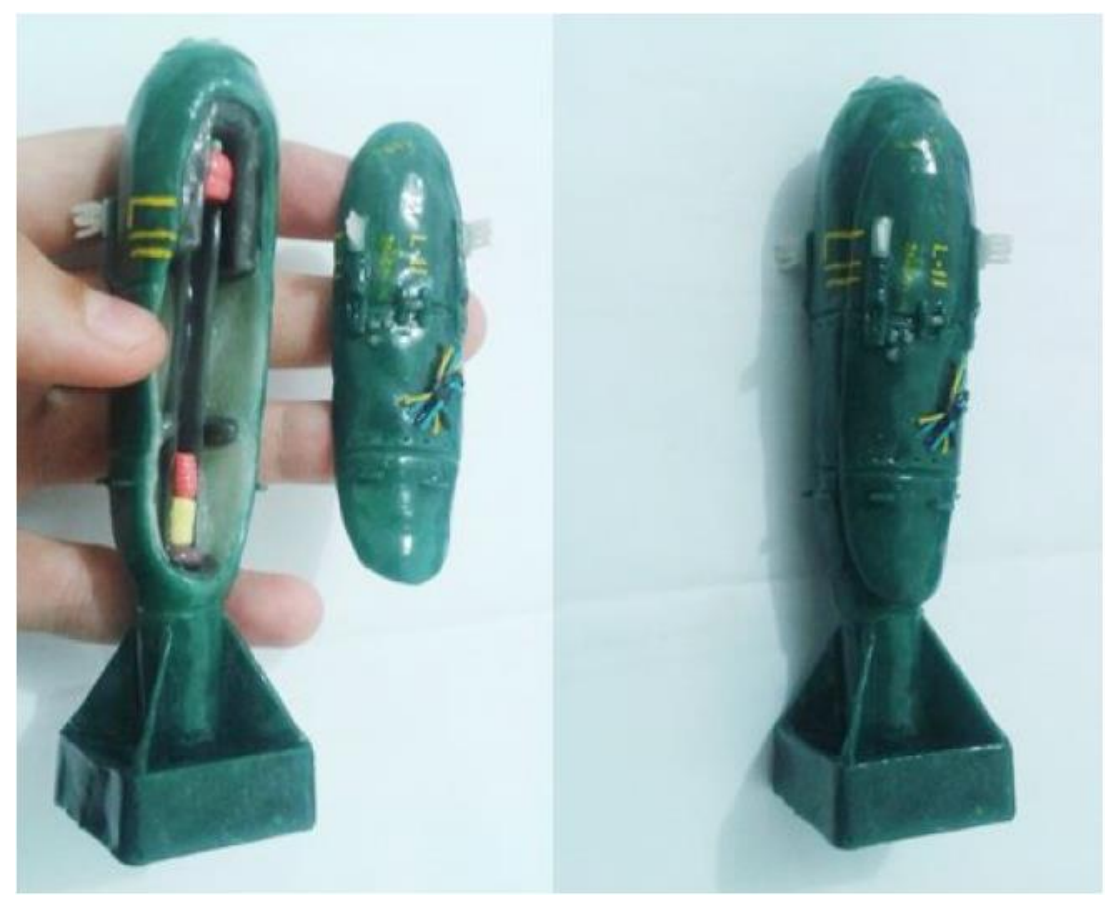

Fonte: Os autores (2020). 
Figura 3 - Representação da bomba Fat Man lançada sobre Nagasaki em 1945

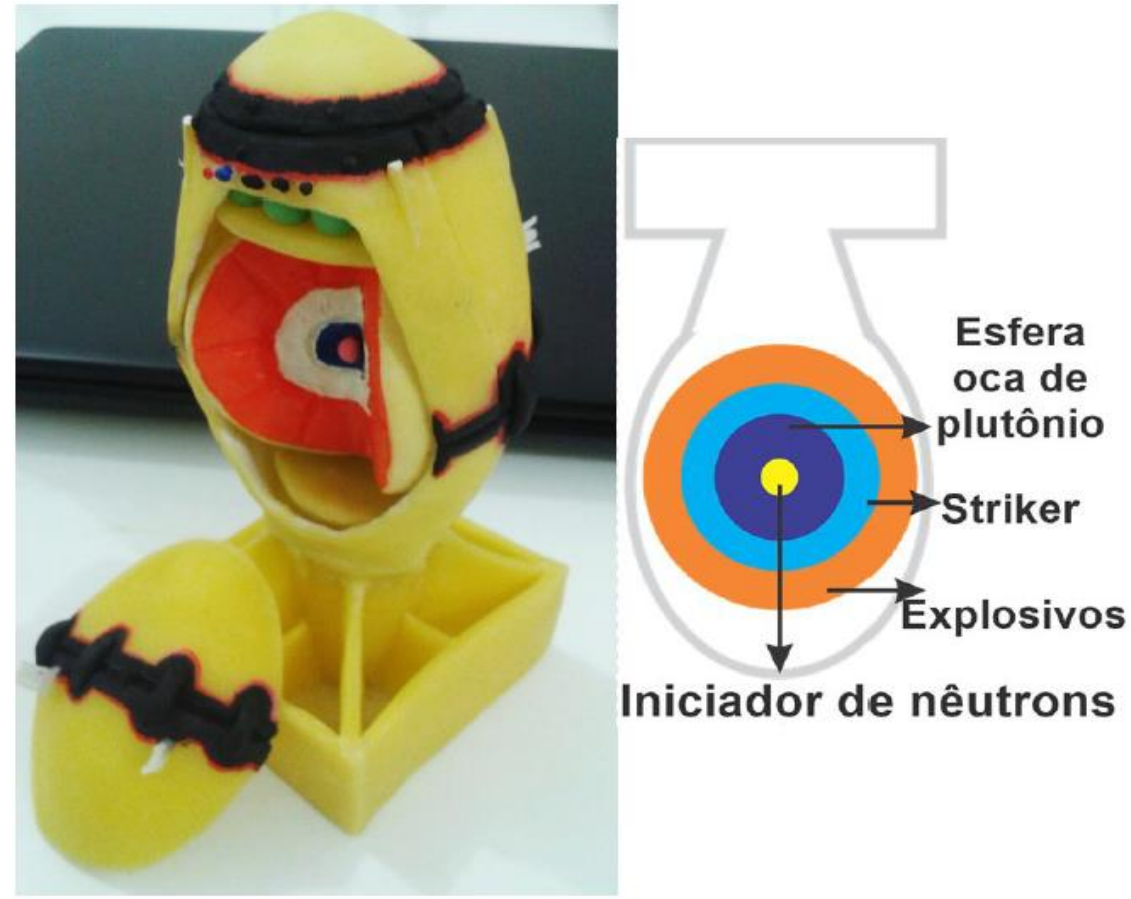

Fonte: Os autores (2020).

Figura 4 - Representação da bomba Tsar Bomb detonada pela Rússia durante a Guerra Fria.
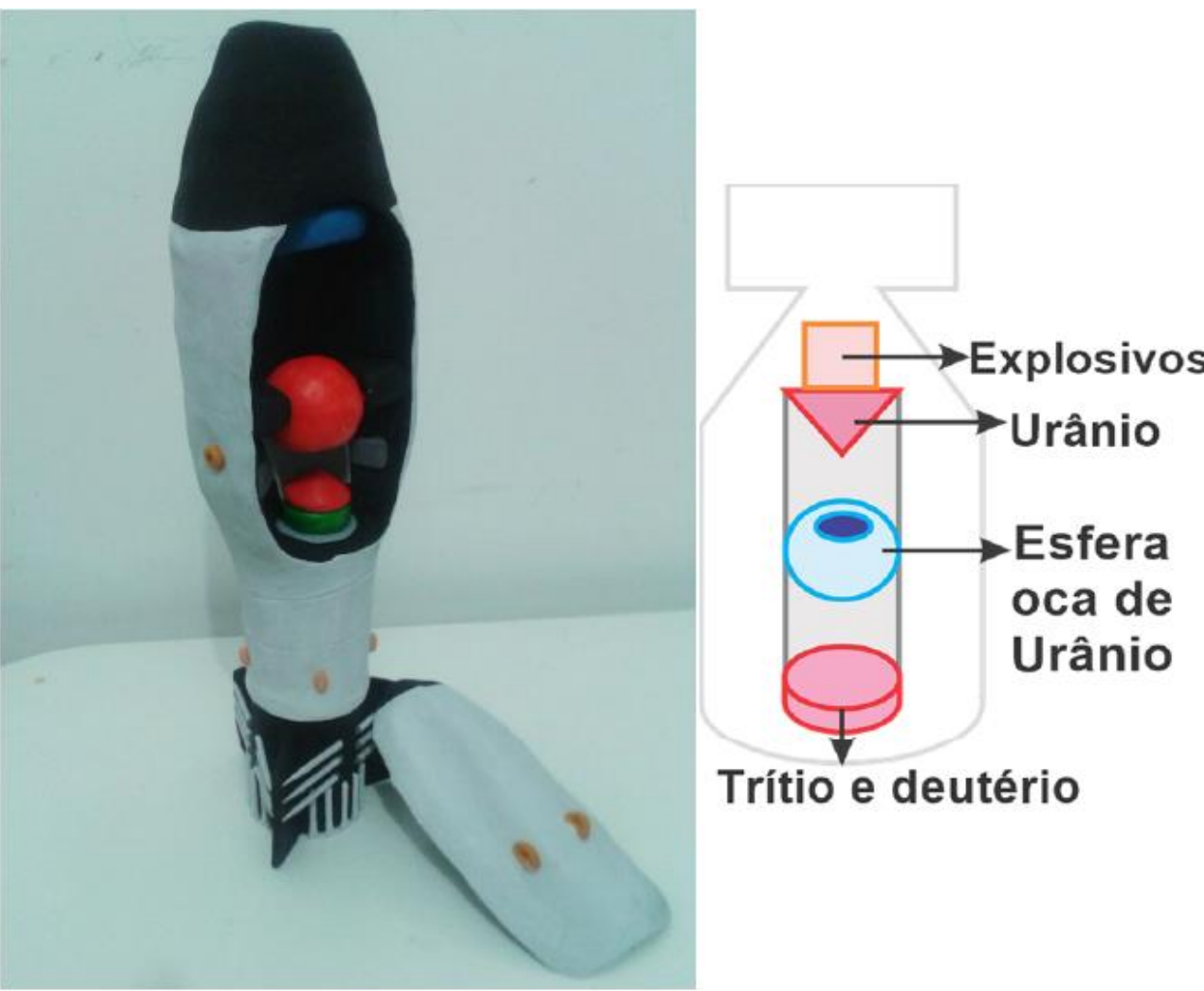

Fonte: Os autores (2020). 
Figura 5 - Representação ${ }^{5}$ do cogumelo formado pela explosão de um artefato nuclear

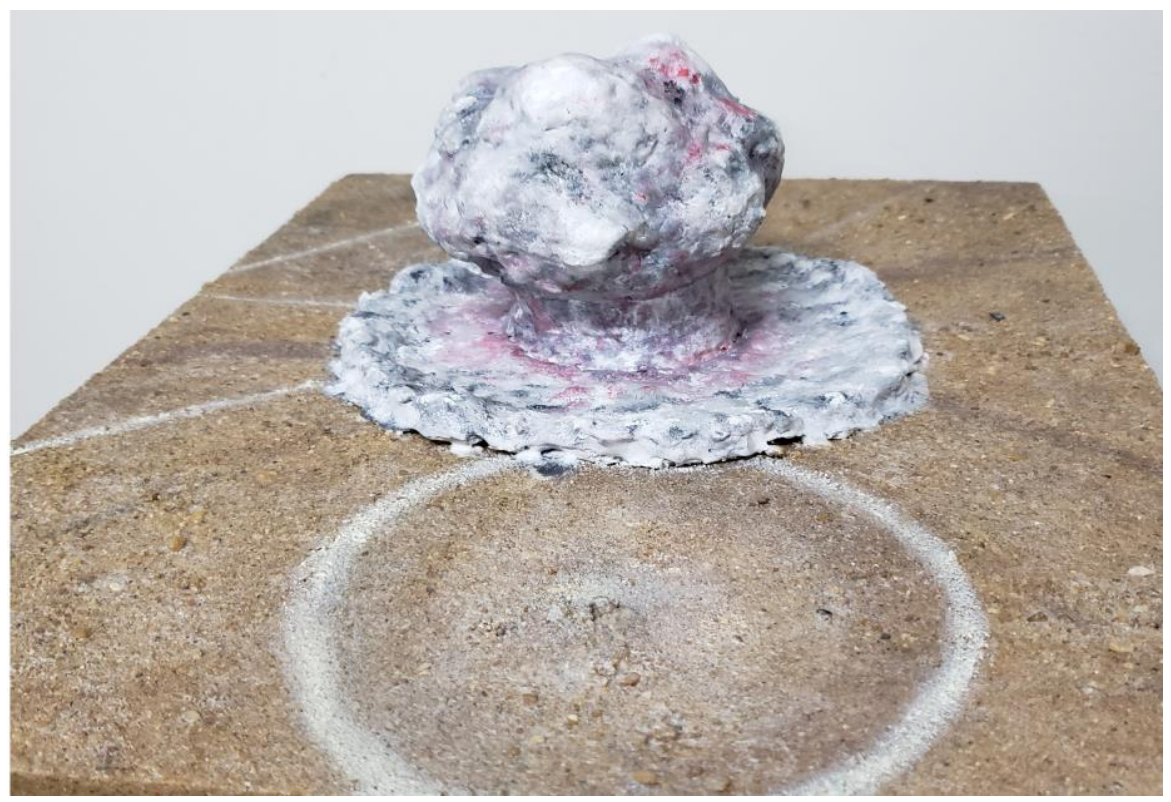

Fonte: Os autores (2020).

\section{Usina Nuclear}

A planta escolhida foi a da usina de Three Miles Island, nos Estados Unidos, em virtude da abundância de material disponível na internet, o que facilitava a avaliação das dimensões e construção da peça. Foi o modelo mais complexo de ser construído.

A base em MDF de $40 \mathrm{~cm} \times 60 \mathrm{~cm}$ foi tratada com cola de madeira. A planta da usina foi adaptada em proporção e a posição dos prédios e construções foi riscada em lápis. O asfalto foi coberto com massa de biscuit à base de amido de milho. As áreas verdes foram texturizadas a partir de fio de sisal picado e tingido, ao passo em que os quarteirões da ilha foram tingidos com tinta de tecido (à base de óleo, portanto, de textura suave) e as ruas foram tingidas com tinta branca fosca (à base de água, de textura seca e arenosa). A água foi pintada em tons de azul e branco e, posteriormente, coberta com cola para isopor e verniz brilhante, resultando em uma textura vítrea. Cada uma das cerca de 40 construções principais, assim como construções secundárias, foram moldadas em papel machê, lixadas, cobertas com massa de biscuit e tingidas. Por fim, foram fixadas na maquete com cola para biscuit.

\footnotetext{
5 A figura representa uma explosão no deserto. O chão é formado por areia, o que permite que cegos identifiquem facilmente os elementos da maquete pelo tato.
} 
Figura 6 - Representação didática da Usina Three Miles Island vista de cima

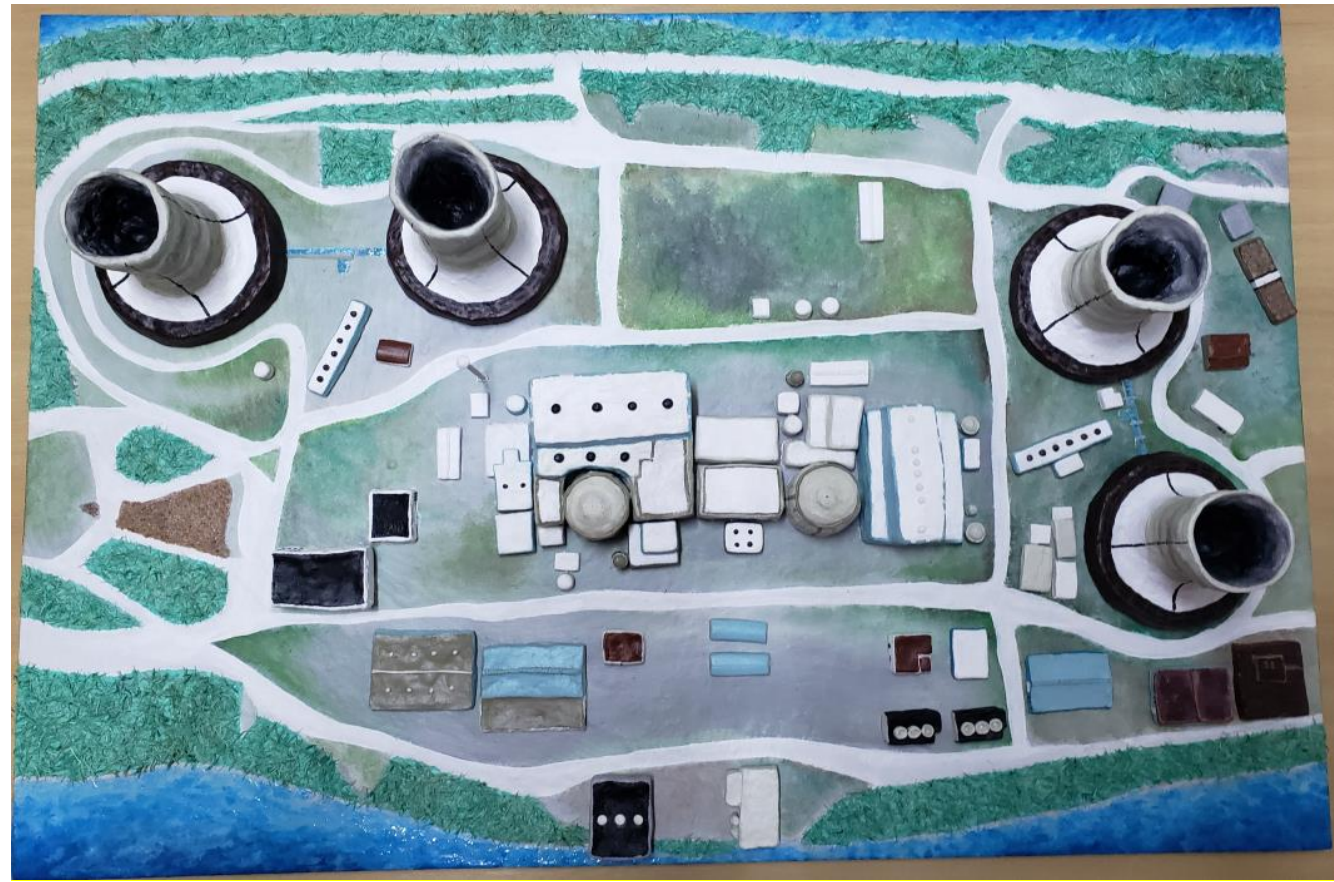

Fonte: Os autores (2020).

Figura 7 - Representação didática da Usina Three Miles Island vista frontalmente

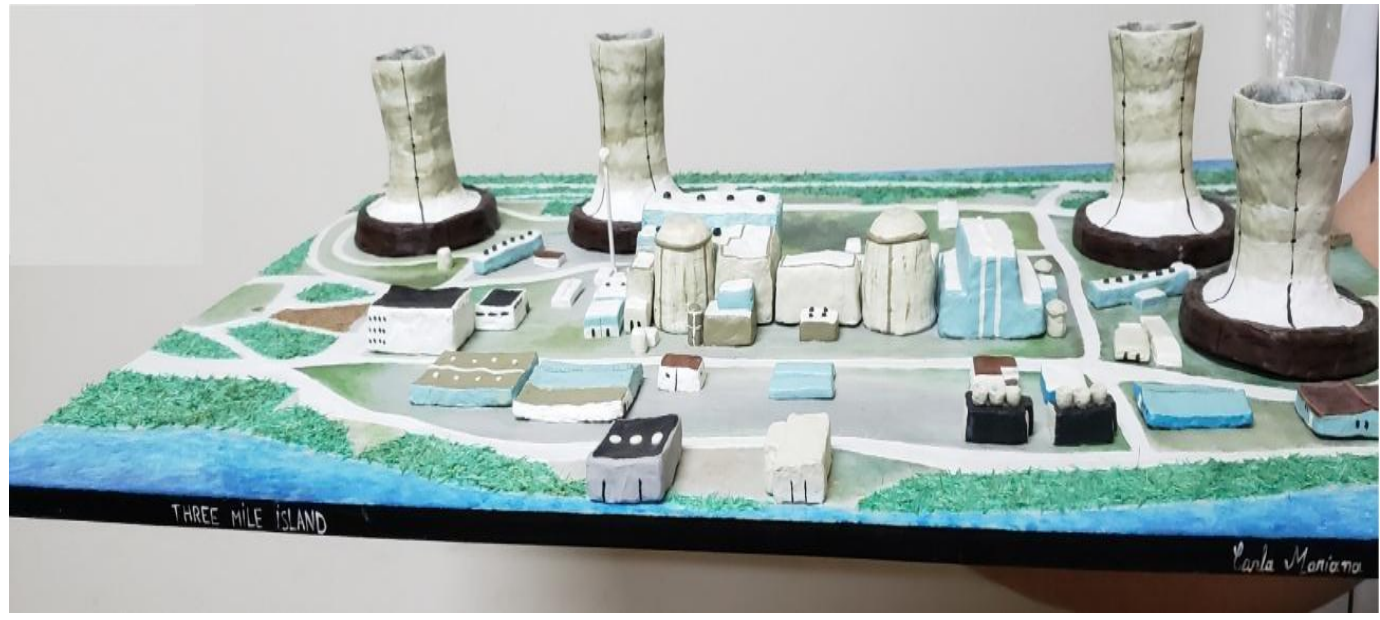

Fonte: Os autores (2020).

Ainda ilustrando a usina nuclear, foram feitas separadamente algumas peças importantes. Um modelo de reator foi construído com base de MDF $10 \mathrm{~cm} \times 10 \mathrm{~cm}$, esqueleto de jornal coberto por uma espessa camada de biscuit e hastes de palitos de churrasco (Figura 8). A peça foi tingida e as varetas de urânio foram cobertas com verniz brilhante de textura vítrea, ao passo em que o restante do corpo do modelo foi coberto com verniz fosco de textura seca. Ademais, foram confeccionados o gerador de vapor, o pressurizador e o acumulador (Figura 9). 
Figura 8 - Representação didática de um reator nuclear visto em corte

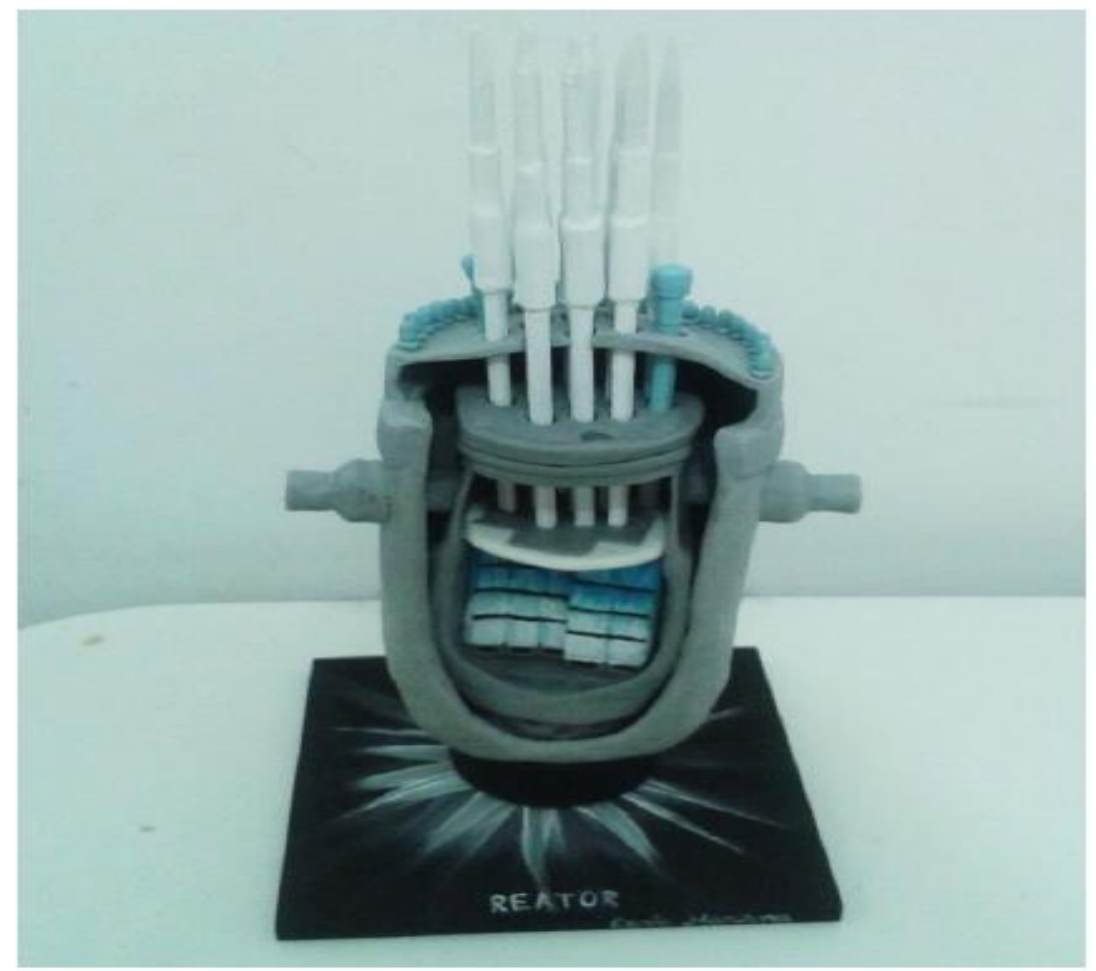

Fonte: Os autores (2020).

Figura 9 - Representação didática do gerador de vapor, o pressurizador e o acumulador

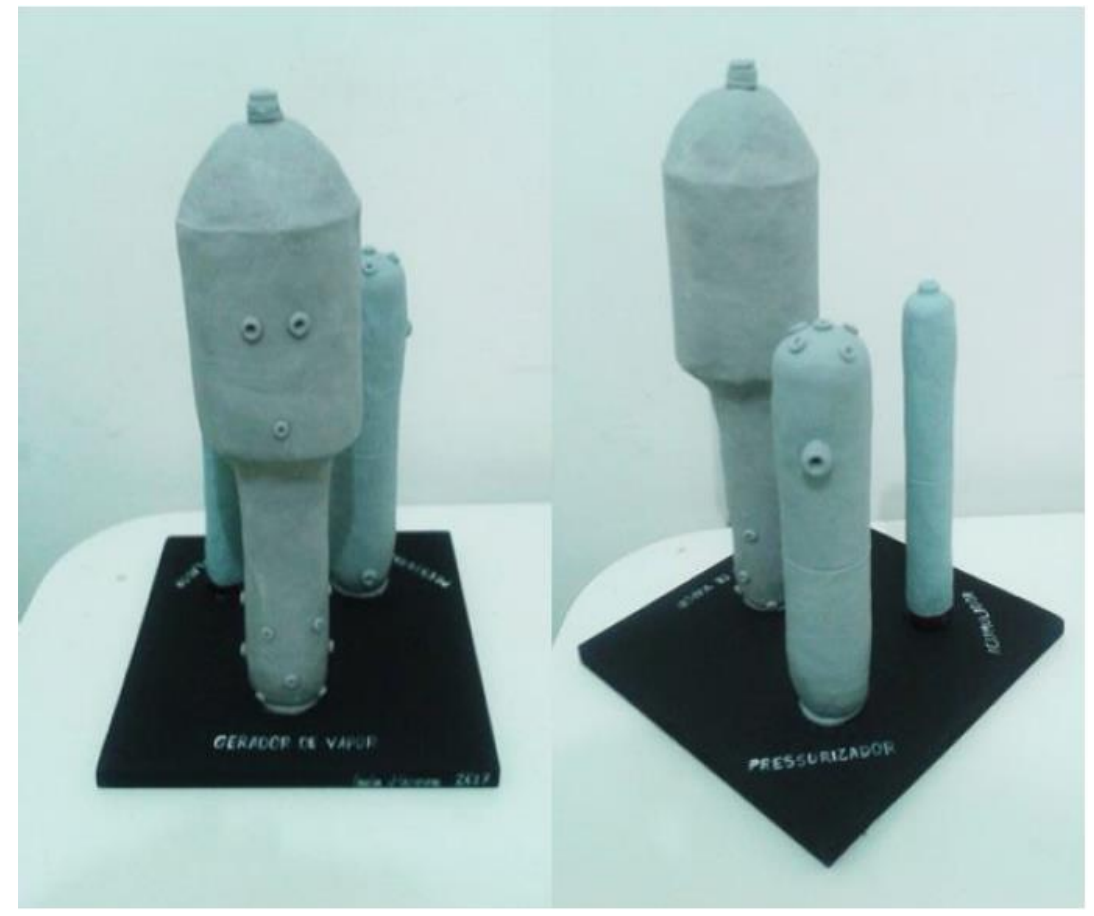

Fonte: Os autores (2020). 


\section{Aplicação das maquetes e relato de experiência}

A construção das maquetes foi planejada de forma que os conceitos da Física Nuclear, a sua aplicação e seu contexto histórico fossem abordados com maior facilidade para o professor ou intermediário, a fim de alcançar os objetivos traçados para o ensino e a divulgação científica do tema em questão. Dessa maneira, foram construídas as maquetes sobre os processos de fusão e fissão nuclear; representações de Chicago Pile 1; o teste Trinity; os três protótipos de bombas; a usina nuclear e suas peças, que apresentam cada detalhe em relevo para realçar o processo tátil das pessoas, em especial, com deficiência visual, no processo de reconhecimento e aprendizagem das etapas, da aplicação e dos conceitos abordados.

O material construído foi apresentado na sétima edição do evento Brincando e Aprendendo (B \& A), realizado pelo Museu Diversão com Ciência e Arte (Dica) da Universidade Federal de Uberlândia, realizado no Uberlândia Shopping. O B \& A tem o objetivo de divulgação científica e tecnológica por meio de atividades educacionais e interativas de diversas áreas do conhecimento, voltadas para a comunidade e alunos da educação básica. O evento teve duração de três dias, em que as maquetes foram apresentadas para centenas de crianças, jovens e adultos, dentre estudantes e frequentadores do shopping.

A atividade, apresentada como divulgação científica, contou com dois mediadores (alunos do curso de Física da UFU), que explanaram as maquetes, começando com o processo de fusão e fissão nuclear, passando pelo Chicago Pile 1, o teste Trinity, os três protótipos de bombas, a usina nuclear e suas peças. Para transpor e explicar os conceitos e aplicações envolvidos nas maquetes, foi adotada ou aplicada uma linguagem que fosse a mais simples possível, evitando termos técnicos desnecessários e adequando as definições científicas (OKUNO; YOSHIMURA, 2010) de acordo com a diversidade de público.

Durante o evento, houve participação de alunos/as com deficiência visual, possibilitando que a proposta de inclusão fosse posta à prova. Em cada etapa ou trajeto de exposição das maquetes, esses/essas alunos/as foram guiados/as e suas mãos direcionadas para cada detalhe das maquetes. Eles/elas conseguiram descrever "precisamente" o que sentiam, e isso confirmou a efetividade das maquetes, em que informações visuais importantes foram possíveis de serem interpretadas ou passadas por meio do toque. Durante a explanação das informações e explicações dos mediadores, esses alunos e o público em geral conseguiram interagir, discutir e compreender os conceitos e aplicações da Física Nuclear. 
Outro ponto importante para a avaliação das maquetes foi a eficácia do material, em relação à resistência, à segurança e ao conforto das pessoas ao tocarem nas maquetes, por meio da observação das reações e relatos dos/as alunos/as que tiveram contato com os modelos. Assim, o resultado da confecção do material foi muito positivo, produzindo peças fortes, resistentes, que provavelmente apresentarão uma alta durabilidade, além de não apresentarem perigo e desconforto às pessoas. O trabalho com texturas e relevos tornou a identificação das peças ao tato mais precisa, facilitando o reconhecimento pelos/as alunos/as com deficiência visual e o trabalho de explanação do docente ou intermediário.

Por fim, em relação à apresentação no evento B \& A, observou-se que o material cumpriu o objetivo de ser chamativo e interessante aos olhos do público e principalmente de ser um recurso didático para os alunos com deficiência e uma ferramenta de divulgação científica, uma vez que proporcionou a comunicação científica para a população sobre o tema em questão. Todos os que passaram pelo estande tiveram curiosidade quanto às maquetes e fizeram perguntas tanto quanto ao significado de cada modelo quanto sobre a confecção dos mesmos. As representações atraíram pessoas de todas as idades e mesmo as crianças mais jovens conseguiram entender o significado básico das maquetes.

Com essa experiência de montagem e aplicação das maquetes no evento de divulgação científica, e a participação no projeto de extensão, os/as alunos/as envolvidos/as conseguiram construir e se desenvolver nos aspectos profissional (docência), cidadão e humano, em que as problemáticas apontadas podem ser resolvidas por meio da atividade abordada neste trabalho. Além disso, a ação de extensão desenvolvida alcançou os objetivos gerais de "um laboratório didático que possibilita utilizar e aprofundar diversas estratégias de ensino para auxiliar na compreensão dos conteúdos" (NOZAKI, 2012, p. 100-101), a integração da sociedade e a Universidade, e o enriquecimento das pessoas envolvidas.

\section{CONSIDERAÇÕES FINAIS}

A apresentação do material retornou resultados promissores, apontando para a eficácia das maquetes no que tange aos objetivos estabelecidos no início do trabalho. A atividade mostrou-se interessante aos olhos do público geral, o que resultou numa participação entusiasmada ao longo da exposição dos modelos no evento e cumpriu com o papel de inclusão de alunos portadores de deficiência visual, os quais exploraram as maquetes com curiosidade e gosto. 
Os próximos passos na pesquisa incluem apresentar o material para mais alunos/as com deficiência visual, visando coletar sugestões de melhoria e verificar em maior escala a eficácia dos modelos no ensino inclusivo e na divulgação científica. Também pretende-se utilizar as maquetes em aulas de disciplinas que abordem a história e os conceitos de energia nuclear do curso de Física Médica da UFU e em escolas públicas, visando avaliar seu impacto como material auxiliar para o ensino. Ademais, deseja-se realizar um minicurso de formação para professores de física da educação básica que envolva a construção das maquetes e o ensino dos conceitos aplicados da Física Nuclear.

Por fim, a ação de extensão apresentada contribuiu significativamente para a formação dos alunos da graduação e para o ensino e divulgação científica às pessoas sobre a Física Nuclear, em especial, as pessoas com deficiência visual.

\section{AGRADECIMENTOS}

Os autores agradecem às agências de Fomento FAPEMIG (Projetos nº APQ-0304915 e APQ-02934-15) e CNPq (Projetos no 421603/2016-0 e 420699/2016-3) pelo apoio financeiro aos pesquisadores. O autor Lucio Pereira Neves recebe uma bolsa de PQ-2 do CNPq (Processo no 314520/2020-1). Monique França e Silva agradece ao CNPq pela Bolsa GD (No 88887.612310/2021-00).

\section{REFERÊNCIAS}

AMARAL, G. K.; DICKMAN, A. G.; FERREIRA, A. C. Educação de estudantes cegos na escola inclusiva: o ensino de Física. In: SIMPÓSIO NACIONAL DE ENSINO DE FÍSICA (SNEF), 18., 2009, Vitória. Caderno de Resumos [...]. Vitória-ES: SNEF, 2009. Disponível em: https://sec.sbfisica.org.br/eventos/snef/xviii/sys/resumos/T0070-1.pdf. Acesso em: 16 jul. 2021.

BAPTISTONE, G. F. et al. A inclusão do aluno cego na educação superior: percepções de professores de um curso de licenciatura em química. ACTIO, Curitiba, v. 2, n. 1, p. 98-121, 2017. Doi: 10.3895/actio.v2n1.6718. Disponível em:

https://periodicos.utfpr.edu.br/actio/article/view/6718. Acesso em: 10 jul. 2021.

CAMARGO, E. P. Saberes docentes para a inclusão do aluno com deficiência visual em aulas de Física. São Paulo: EdUnesp, 2012. Disponível em:

https://repositorio.unesp.br/bitstream/handle/11449/113714/ISBN9788539303533.pdf?sequen ce=1\&isAllowed=y. Acesso em: 10 jul. 2021. 
CARVALHO, J. F. O espaço da energia nuclear no Brasil. Estudos Avançados, São Paulo, v. 26, p. 293-307, 2012. Doi: 10.1590/S0103-40142012000100021. Disponível em:

https://www.scielo.br/j/ea/a/wyz7HtbndJ5cdXLchMSTNPm/?lang=pt. Acesso em: 10 jul. 2021.

CARVALHO NETO, R. A.; FREIRE JÚNIOR, O.; ROCHA, J. F. M. Revelando o caráter determinístico da mecânica newtoniana: uma ponte para o ensino da Física moderna no ensino médio. Ideação, Feira de Santana, n. 3, p. 51-68, 1999. Disponível em:

https://www.yumpu.com/pt/document/read/12871339/revelando-o-carater-deterministico-damecanica-newtoniana. Acesso em: 10 jul. 2021.

COSTA, M. C. R.; BORTOLIERO, S. T. O jornalismo científico na Bahia: a experiência da seção "Observatório" do jornal A Tarde. Diálogos e Ciência, Salvador, v. 1, n. 12, p. 12-24, 2010. Disponível em:

http://www.jornalismocientifico.com.br/jornalismocientifico/artigos/jornalismo_cientifico/arti go31.pdf. Acesso em: 10 jul. 2021.

DAL TOÉ ROSS, J.; VOOS, I. C. O ensino de ciências da natureza para estudantes cegos: uma análise nos anos iniciais do ensino fundamental. In: ENCONTRO NACIONAL DE PESQUISA EM EDUCAÇÃO EM CIÊNCIAS, 11., 2017, Florianópolis. Anais [...]. Florianópolis: UFSC, 2017. Disponível em: http://www.abrapecnet.org.br/enpec/xienpec/anais/resumos/R1713-1.pdf. Acesso em: 10 jul. 2021.

FERREIRA, A. C.; DICKMAN, A. G. Ensino de física a estudantes cegos na perspectiva dos professores. In: In: ENCONTRO NACIONAL DE PESQUISA EM EDUCAÇÃO EM CIÊNCIAS, 6., 2007, Florianópolis, 2007. Anais [...]. Florianópolis: UFSC, 2007. Disponível em: http://abrapecnet.org.br/atas_enpec/vienpec/search0.html. Acesso em: 15 jul. 2021.

HEWITT, P. G. Fundamentos de física conceitual. 9. ed. Porto Alegre: Bookman, 2009.

MACHADO, A. C. S. Ensino de física para deficientes visuais: uma revisão a partir de trabalhos em eventos. 2010. Trabalho de Conclusão de Curso (Graduação em Física) Universidade Católica de Brasília, Brasília, 2010.

MIZRAHI, S. S. Mulheres na física: Lise Meitner. Revista Brasileira de Ensino de Física, São Paulo, v. 27, n. 4, 2005. Doi: 10.1590/S1806-11172005000400001. Disponível em: https://www.scielo.br/j/rbef/a/WfywcNbK5v6hZNgnRDvJCpz/?lang=pt. Acesso em: 15 jul. 2021.

MORAIS, A.; GUERRA, A. História e filosofia da ciência: caminhos para a inserção de temas física moderna no estudo de energia na primeira série do ensino médio. Revista Brasileira de Ensino de Física, São Paulo, v. 35, n. 1, 2013. Doi: 10.1590/S180611172013000100018. Disponível em: https://www.scielo.br/j/rbef/a/w6tJKQgQh7PY6wGTxQ8hGjw/?lang=pt. Acesso em: 15 jul. 2021.

NEPOMUCENO, T. A. R.; ZANDER, L. D. Uma análise dos recursos didáticos táteis adaptados ao ensino de ciências a alunos com deficiência visual inseridos no ensino fundamental. Benjamin Constant, Rio de Janeiro, v. 1, n. 58, 2015. Disponível em: http://revista.ibc.gov.br/index.php/BC/article/view/325. Acesso em: 10 jul. 2021. 
NOBELPRIZE.ORG. Otto Hahn: biographical. The Nobel Prize, Stockholm, 1944.

Disponível em: https://www.nobelprize.org/prizes/chemistry/1944/hahn/biographical/. Acesso em: 20 jul. 2021.

NOZAKI, J. M. Os significados e as implicações da extensão universitária na formação inicial e na atuação profissional em educação física. 2012. 135 f. Dissertação (Mestrado em Ciências da Motricidade) - Instituto de Biociências, Universidade Estadual Paulista, Rio Claro, 2012. Disponível em: https://repositorio.unesp.br/handle/11449/87424. Acesso em: 7 jul. 2021.

NUNES, S. S.; LOMONACO, J. F. B. Desenvolvimento de conceitos em cegos congênitos: caminhos de aquisição do conhecimento. Psicologia Escolar e Educacional, Campinas, v. 12, n. 1, p. 119-138, 2010. Doi: 10.1590/S1413-85572008000100009. Disponível em: https://www.scielo.br/j/pee/a/zvVp8FNBfyxH9b3FwJYskPx/?lang=pt. Acesso em: 10 jul. 2021.

OKUNO, E.; YOSHIMURA, E. M. Física das radiações. São Paulo: Oficina de Textos, 2010.

PEREIRA, D. R. O.; AGUIAR, O. Ensino de física no nível médio: tópicos de física moderna e experimentação. Ponto de Vista, Viçosa, v. 3, n. 1, p. 65-81, 2006. Disponível em: https://periodicos.ufv.br/RPV/article/view/9743. Acesso em: 15 jul. 2021.

SIMONS, M. Radiation fears infect Brazil after accident. The New York Times, New York, 2 dez. 1987. Disponível em: https://www.nytimes.com/1987/12/02/world/radiation-fearsinfect-brazil-after-accident.html. Acesso em: 18 out. 2020.

UFRGS - UNIVERSIDADE FEDERAL DO RIO GRANDE DO SUL. As diferenças entre: fissão e fusão nuclear. Divulgando Ciência, Porto Alegre, 29 nov. 2016. Disponível em: https://www.ufrgs.br/divulgacaodaciencia/2016/11/29/as-diferencas-entre-fissao-e-fusaonuclear/. Acesso em: 23 ago. 2021.

Submetido em 16 de abril de 2021. Aprovado em 12 de julho de 2021. 